\title{
Barriers and Enablers of Education Equality for Transgender Students
}

\author{
STEPHANIE BURNS \\ Queen's University Belfast, UK
}

RUTH LEITCH

Queen's University Belfast, UK

JOANNE HUGHES

Queen's University Belfast, UK

\begin{abstract}
This paper reports the results of research on education inequalities in Northern Ireland, carried out by a team from Queen's University Belfast on behalf of the Equality Commission for Northern Ireland. A focus group and individual interviews were carried out with key stakeholders (transgender individuals, parents of transgender students, and advocates from organisations that support transgender students) to explore and understand the contributory factors and manifestation of educational inequalities for transgender students at different stages of their education, along with potential enablers of equality. The main barriers found were: gender stereotyping in schools; a lack of awareness and understanding of trans issues; a lack of guidance for schools; inflexibility around school rules; exclusion (including selfexclusion due to feelings of not being accepted); the timing of transition; difficult enrolment processes; moving away from home; and inappropriate facilities. Enablers of education equality for transgender students included: central directives and joined-up working between government departments; training for school staff; flexibility in school practices; and a systematic approach to data collection concerning the experiences of transgender students.
\end{abstract}

\section{Keywords}

transgender, inequality, inclusion, attainment, access

\section{Introduction}

Over the last several decades, a groundswell of research, policymaking and practical resources for education institutions has emerged regarding the identification and response to inequalities faced by school pupils and college students who identify as lesbian, gay and bisexual (LGB). What has been lacking in this progression are studies, policies and resources that explore the experiences of transgender (' $\mathrm{T}$ ', or trans) individuals and the challenges they face in educational settings. Schneider (2010) describes how the common 'LGBT' acronym was derived from the merging of transgender ( $\mathrm{T}$ ) activism with the already-established LGB movement, due to the perceived connection between gender identity and sexual orientation. Schneider argues that in order to more effectively meet the needs of transgender students (identified, according to Monro (2003: 433) as 'cross-dressers, transsexuals, androgynes, intersexes (people born with a mixture of male and female 
physiological characteristics), drag queens and kings, third gender people and other transgender people'), the individual identities and needs of this marginalised community must be investigated and understood separately from the LGB community. The overarching aim of the research study from which this paper draws was to identify education inequalities in Northern Ireland with regard to educational access, attainment, progression and destination across nine 'equality' grounds, of which gender was one (sexual orientation was treated as a separate equality ground). This paper presents the findings for transgender individuals in particular.

In the UK, research by Whittle, Turner and Al-Alami (2007) on transgender people's experiences of discrimination looked at the school experience as one arena in which inequality for trans people occurs. They found that $64 \%$ of young trans men and $44 \%$ of young trans women experience harassment or bullying at school, not just from their fellow pupils but also from school staff including teachers. In regard to educational attainment, the report found large differences between achievement levels in the trans population compared to the UK average; while many trans people leave school after completing Level 2,34\% obtain a degree or higher degree (later in life), compared to the UK national average of only $27 \%$. In attempting to explain this discrepancy, the authors make two suggestions. Firstly, while some trans individuals leave school early due to negative experiences such as bullying, they may return to education as mature students and do particularly well, given the life skills necessary to re-enter the system and fully transition as an adult. Secondly, given that gender reassignment is a complex and difficult undertaking, it may be the case that those who are more highly educated find it easier to navigate the process.

A report commissioned by the government in Northern Ireland (McBride 2013) highlighted the challenges faced by gender variant and transgender young people (age 25 and under) in their education. The report revealed that issues of gender identity, gender dysphoria and transgender issues are absent from Northern Ireland's national curriculum for schools. As a result, McBride argues that this has led to a lack of awareness in Northern Ireland as a whole about trans issues and 'disempowers young trans people from having the necessary awareness to understand their gender identity' (McBride 2013: 4). The report further states that the strict dress codes set by many Northern Irish schools often do not match the gender identity of transgender students, which can cause stress, anxiety and discomfort, and may lead to truancy; missing school time, in turn, has for many years been negatively correlated with educational attainment (Wiley and Harnischfeger 1974; Buscha and Conte 2014). Furthermore, some young people included in McBride's report (2013) claimed that they had heard their teachers expressing prejudiced views, or that their schools had reacted with disbelief and insensitivity to 
their situation. McBride's qualitative study also found that transphobic bullying was a problem in school settings, sometimes leading to trans pupils feeling isolated to the extent that they suffer poor mental health, which again has a negative influence on their learning. All of these issues may combine to lead to educational inequalities via the hindrance of trans young people's personal, social and emotional development.

Pugh (2010) has offered guidance on the promotion of trans equality within higher education institutions. The steps include ensuring awareness of gender identity issues and developing proactive policies and procedures that are inclusive of trans people, for example in considerations of: accommodation and single-sex facilities; confidentiality; criminal record checks; the wording and process of awarding degree certificates; dress codes; the wording of forms and questionnaires; all records; recruitment; sports; and support groups. The report also recommends that policies should protect the rights of trans people to dignity at work and in educational settings, and that any decision to monitor gender identity, while potentially useful in analysing patterns of inequality and identifying ways to support trans staff and students, should be taken in consultation with them in order to gauge support for doing so.

At this time, the UK has no official statistics relating to the number of transgender people; this deficit of information forms the backdrop to the present study. The Equality Commission for Northern Ireland (an independent public body established in the wake of the Northern Irish peace process with responsibility to promote equality of opportunity and challenge discrimination) commissioned this research with a view to illuminating (where possible) current education inequalities, as well as barriers and enablers of equality for particular groups.

\section{Methods}

To explore barriers and enablers of education inequality for transgender students, specifically in terms of access issues, progression through school, achievement, and destinations after compulsory schooling, one focus group and two individual interviews were carried out with key stakeholders (two transgender individuals, three parents of transgender students, and two advocates from organisations that support transgender students) between October 2013 and December 2013. The participants (most of whom had previously met and were familiar to each other) were identified through snowball sampling via the research funder's contacts. The participants were assured of anonymity as their names and their roles within organisations were removed from raw data and the resultant reports, and pseudonyms were used where necessary. The focus group and interviews were audio- 
recorded and transcribed. The data were analysed using a thematic analysis approach.

\section{Results}

The themes that emerged from the data analysis were identified as barriers at the different stages of education, or as general enablers of education equality. Each is outlined in turn below.

\section{i. Barriers at Primary and Post-Primary School}

The research participants identified six barriers to equality during compulsory schooling (primary and post-primary school); gender stereotyping; a lack of awareness; a lack of central guidance; inflexibility; exclusion; and the timing of transition.

\section{a. Gender Stereotyping}

Parents of gender variant children reported that the gender binary and gender stereotyping that exists in schools can make children feel like they do not belong in their school and contribute to their disengagement:

In nursery school, the things you need to look at are the dress-up boxes, where if a boy comes out in a princess dress, other kids will say something e.g. [name] dressed up as a girl today'. Even things like stickers for hanging your coat - it will be a fire engine for guys, a fairy for girls. Even practical things would help - let the young person select their own sticker (Parent).

\section{b. Lack of Awareness and Understanding of Trans Issues}

It was reported that there is also a general lack of understanding in educational institutions of what transgender issues are, including a lack of understanding around terminology and what trans issues can mean for different people. This can result in sensitive issues not being dealt with properly; for example, one parent claimed that some teachers view gender variance as 'just part of their development - they'll grow out of it'. Similarly, another parent argued:

There are some teachers who think it is 'good' for someone who presents as a boy to be reinforced in that male role, and the same for females as well. The lack of understanding there amongst male teachers is a real problem. If they can't recognise it, then they can't deal with it (Parent).

\section{c. Lack of Central Guidance and Policy}

The decentralisation of policy in education in Northern Ireland and the lack of any central guidance for schools as to how they can provide support to gender variant children was identified as another key barrier as it can add to the marginalisation of individual pupils: 
The likelihood is that they are going to be presented with a gender variant child, at some point. That will inform the reaction to what happens. It is reactive, and not proactive, because then, whenever it does happen, it becomes about that person. It's not about the general issue, it is very personalised on one person (Transgender individual).

This marginalisation can have a direct impact on young people's progression and learning:

Because there are no guidelines, it's the teacher's personal feelings and opinion on it. And if you're not lucky enough to get someone who knows or understands or is openminded, then the child suffers. We have had cases where a teacher has not been supportive, and is insisting on using former names, the wrong pronoun, and is insistent on that. And then the child's learning starts to be affected by that because they don't want to go to school because of the distress it causes (Advocate).

However, there was recognition amongst representatives and stakeholders that even supportive schools and teachers are in a difficult position when there is no guidance. 'Fear' was mentioned frequently in the focus group; one participant claimed that teachers 'fear legal action because there is no policy...they don't know what to say...so they [don't] say anything':

Teachers can also be fearful. They said to me it is the lack of guidance - there may be a child presenting to them, and no matter what they feel about it, the governors and the senior management at the school don't have a policy on it, and there's no policy on it from the [local education authority], so the teachers themselves are caught between a rock and a hard place. They don't know the positive benefits of treating the child as who they are against the trouble that they may get into for doing that... supportive teacher can be very fearful of what to do...The head teachers we were talking to want so much to know how to deal with these things. They wanted the Department [of Education] to tell them what is our policy supposed to look like, how do we enforce these and what training can we access (Advocate).

One parent of a transgender young person stated that this barrier applies to non-teaching staff too - school counsellors also need more guidance in how to help and support trans young people:

My child is seeing a counsellor now, and the counsellor will not go into anything about transgender. They want to go into past family life, daddy issues, all that, but they won't go into transgender because it's something that she's not trained in - but that's what my child needs...she needs someone who has training and has experience to talk to. That's where the difficulty is (Parent).

\section{d. Inflexibility in School Rules}

Strict school rules (along with a lack of central guidance on dealing with transgender issues) can place further hurdles in front of gender variant young people such as social exclusion and school exclusion:

If you are dealing with this as a person on your own, there are so many rules about what classes you take, what uniform you wear, where you get changed, what toilets 
you use - it is a minefield. It is one person trying to pick their way through a minefield that at any moment could go horrendously wrong (Transgender individual).

A parent explained the difficulties that can arise from the common segregation of pupils at the post-primary level in Northern Ireland by biological sex (approximately one fifth of post-primary pupils in Northern Ireland attend single-sex schools): 'I am scared that if I say, my child is a boy, they will say "well, this is a girls' school - get her out."'

\section{e. Exclusion}

Another identified barrier to transgender people's attainment and enjoyment of school was exclusion. One form of this was self-exclusion from certain classes or from school altogether due to feelings of not being accepted, which reduces the breadth of learning experienced by transgender children:

What you find then is that the children exclude themselves from things that other children take for granted. You'll find that many gender variant children don't do PE. And then there's all the facts about mental health and wellbeing being related to exercise. Then you also have the issue of school trips, and overnights. A gender variant child will tend not to go on the school trip (Advocate).

When my child is at PE, she is left standing in the corridor for an hour. [Name] won't even go to RE now, so that's another class she's skipped. It is compulsory, but she hangs about in the corridors for half an hour... There's an issue there that the schools aren't providing an alternative to that - some study time or something (Parent).

Social exclusion by peers was also a commonly reported issue, often leading to a child moving from one school to another - this was the case with 'most of the children' who had contacted one of the LGB\&T support groups represented in the focus group. As one parent explained, 'The girls always excluded [name] - she was always with the boys. If only I'd known, or if only a teacher had have known, then the child could have been helped from [Year 6]. Instead, I had to move her school.'

\section{f. The Timing of Transition}

It was reported that gender variant young people will often wait until they can leave school to start their transition - no matter how unhappy this makes them and how much stress this adds to their lives - just to try to get through school without being bullied or excluded:

Often a parent will make a decision - the child will just go to school as this other gender - for the sake of not being bullied, just to not rock the boat; just to get them through their [post primary exams] or whatever, and get them out the other side. Then what you'll find is, they'll go to a [college], and then they'll change. (Advocate). 
[Name of child] has Facebook, and she put on it gender: male, and I said, please, don't add anybody on Facebook from where we live, because I know what people are like. And that is why I won't let her transition while at school - there is no way on this earth I would. No way. It would make her life a living hell (Parent).

One transgender individual argued that current 'society' is not conducive to transitioning any earlier: 'we can tinker around with toilets, badges and all that, but this is fundamentally what we are talking about - you cannot transition in school. The timing is not right, and society is not right'.

\section{ii. Barriers at third level education}

While going to college or university was considered by some participants to be a potential refuge for transgender people in the face of unwelcoming workplaces, three further barriers to equality were identified which were specific to entering third level education: enrolment processes; the move away from home; and inappropriate facilities.

\section{a. Enrolment processes}

It was claimed that individuals who are in the process of transitioning can face varying levels of difficulty when enrolling in college or university depending on ID requirements and the straightforwardness of altering official qualifications documents.

\section{b. Moving Away from Home}

Some parents reported that their children were very keen to move away after compulsory education because of the 'fresh start' they hoped this would give them, despite the 'support structure' at home offered by parents or family: '[My child is] talking about living in America, and she just wants to escape everything that is to do with her life now. Where nobody knows her as a girl. She was looking at London to go to college.'

\section{c. Inappropriate Facilities}

Universities and colleges may have single-sex halls of residence or inadequate facilities which can place barriers on transgender individuals who have plans to go on to further study:

Quite a few do go away, but again, we have one comment from a young trans person who did go away, and they were in female halls, and found that experience very negative...That person ended up leaving after two weeks and coming home. But then it's about questions around passing, you know. It depends on the college or university, and whether they have the right facilities or whatever (Advocate). 


\section{iii. Enablers of Education Equality}

The enablers of educational equality for transgender students were grouped into four key thematic areas: the establishment of central directives and coordinated government approaches; additional training for school staff; increased flexibility in school practices; and increased monitoring and data collection on the experience of transgender students.

\section{a. Central Directives and Coordinated Approaches}

Representatives of the transgender community interviewed for this study believed that schools should be required to include measures to address transphobic and homophobic bullying in their anti-bullying policies. The current legislation (from The Education and Libraries (Northern Ireland) Order 2003) was deemed too vague. Furthermore, they stated they would like to see better mechanisms of feedback to parents when bullying occurs:

Schools should be required to monitor and report the different forms of bullying that
pupils report, and that should be available to parents so that they can see how things
are progressing. Rather than parents constantly trying to ring the school and say
"how is that going? I last spoke to you 6 months ago and am waiting for a response
back" (Advocate).

Schools in Northern Ireland are not currently deemed 'public authorities'; as such, Section 75 of the Northern Ireland Act 1998 (the duty of public authorities to promote equality of opportunity) does not apply to them. Some participants believed that both curriculum reform and the designation of schools as public authorities under the Section 75 equality legislation would help to raise awareness of transgender issues:

Why is it that the only time gender is raised in a school is when it is raised by a child, rather than pupils being educated about what it means to be trans or gender variant? Section 75 applying to schools and the curriculum would really help that (Advocate).

Coordinated approaches between government departments and also between child and adult mental health and psychology services were likewise viewed as strategies which could help support children who are still at school:

At the minute you hear when they are finished with the CAMHS [Child and Adolescent Mental Health Services] team they are sort of dropped, and then expected to engage with the adult services from the start...We need to put something in place a lot sooner...It's not good enough to say, what do we do when they turn 18 ? By that stage the person has already been bullied, already lived 16/17 years in the wrong gender...it has already affected their mental health (Parent). 


\section{b. Training for School Staff}

Participants spoke of the positive impact of supplementary training on transgender issues for school staff in terms of aiding understanding and giving advice for schools on how to support trans young people:

Of course training would help for all staff, including administrators, because they are party to some very sensitive information. A lot of the young people I work with have a really good rapport built up with the administrative staff. That's who they'll go and speak to or have a yarn with (Advocate).

One participant stressed that it is not helpful if schools persistently refer to outside agencies to deal with transgender issues within a school; the capacity to deal with these issues needs to built from within. As one advocate for transgender students explained, "bringing in statutory services - "it is out of our hands" - it is maybe not the most appropriate response... Rather than come out and engage...it removes the responsibility for dealing with it.'

\section{c. Flexibility in School Practices}

Some participants in these interviews reported how small practical changes and increased flexibility in school practices can have a big influence on the extent to which a young person feels accepted and comfortable in school. One advocate gave the example of an all-girls school they worked with, where 'two pupils [are] presenting as male. The teachers have all been told to use male names and pronouns, and they are allowed to wear trousers into school.'

\section{d. Increased Monitoring of the Experiences of Transgender Young People}

Representatives of the transgender community stressed that knowing more about the school experiences of transgender young people was necessary to begin tackling inequalities. According to an advocate, '[Local government research studies] should include questions on transphobic bullying or gender-based bullying. Because at the minute, we don't know. There's no data.'

\section{Conclusions}

The qualitative data reported in this paper reveal the barriers to education equality that transgender people in schools and colleges in Northern Ireland are confronted with, as well as enablers which may help to overcome these challenges. With no quantitative data available to analyse, it is impossible to know trends in attainment, rates of entry to third level education and beyond, or other statistical educational indicators for transgender students. These omissions represent an inequality in themselves. 
The barriers and enablers of education equality for transgender students reported here reflect those that have been reported in previous literature, particularly the findings regarding gender stereotyping and transphobic bullying, exclusion, and the need for central directives, policies, and training for school staff. Structural-level changes (equality legislation, revision of school curricula, policy guidance, and teacher/staff training) are vital for addressing fundamental challenges, while changes in day-to-day classroom practice and school-level structures can help to overcome daily experiences of discrimination and distress. Increasing the current levels of data collection on the experiences of transgender individuals (and having data collection processes that are devised in consultation with them) would be useful for the identification of trends in inequalities as well as the identification of promising practices that support trans staff and students.

\section{References}

Buscha, F. and Conte, A. (2014) The impact of truancy on educational attainment during compulsory schooling: a bivariate ordered probit estimator with mixed effects. The Manchester School, Issue 1, Volume 82, pp. 103-127.

McBride, Ruari-Santiago (2013) Grasping the Nettle: The Experiences of Gender Variant Children and Transgender Youth Living in Northern Ireland. Belfast: Institute for Conflict Research.

Monro, Surya (2003) Transgender politics in the UK. Critical Social Policy, Issue 4, Volume 23, pp. 433-452.

Pugh, Ellen (2010) Trans staff and students in Higher Education. London: Equality Challenge Unit.

Schneider, Wendy (2010) Where do we belong? Addressing the needs of Transgender students in higher education. The Vermont Connection, Volume 31, pp. 96-106.

Whittle, S., Turner, L. and Al-Alami, M. (2007) Engendered Penalties: Transgender and Transsexual People's Experiences of Inequality and Discrimination. London: The Equalities Review.

Wiley, D. and Harnischfeger, A. (1974) Explosion of a myth: Quantity of schooling and exposure to instruction, major educational vehicles. Educational Researcher, Issue 4, Volume 3, pp. 7-12. 